\title{
Trauma, women's mental health, and social justice: Pitfalls and possibilities
}

\author{
Emma Tseris \\ Routledge, Australia, 2020 \\ ISBN 9780367660277, pp.138, paperback, NZD86.89
}

$\mathrm{T}$

This book encapsulates some of the central tensions in social work that have occurred historically and occur today. Where should social work place its energies in the change-making endeavour? While what sets social work apart from other helping professions is its commitment to an examination of power and oppression in relation to social justice, often where it ends up focussing is in keeping people's heads above water in relation to access and advocacy or in helping people "fix" themselves through therapeutic processes. (See for example, Payne, 2021, or Dominelli, 2003, for a further discussion on approaches.) This is often evident for social workers working in mental health systems co-opted by medical models, but also occurs in relation to our work with trauma.

Emma Tseris is a Lecturer in Social Work and Policy at the University of Sydney and was previously a social worker working in the child and adolescent mental health area. She has published extensively in the areas of critical mental health and gender issues and brings both her academic and practice experience to this book. Her central premise is that, while trauma-informed theories may have come some way in validating women's experiences of gender-based violence, and moved us beyond psychiatric paradigms of symptom presentation, we need to be careful of this "new" view and not accept it without question. She advocates for a critical consideration of trauma-based models which, for the most part, still locate the problem and solutions within women, and ignore the socio-political and power contexts that are the sources of/cause the trauma in the first place.
Chapter One sets the scene, beginning with an introduction to trauma paradigms, situating it within a post-structuralist and feminist understanding that the defining of trauma itself occurs within socio-political and professional contexts which may not always place the voices of women service users at the forefront.

Chapter Two considers the evolution of mental health and trauma discourses and sits current views within a neoliberal paradigm which encourages personal responsibility for recovery and change and paints all women who have experienced trauma as "damaged". While a strengths perspective, focus on resilience and recovery-oriented approaches appear to move the narrative towards more consideration of social causation, Tseris contends that "they are often limited by their ongoing acceptance of notions of individual 'dysfunction', an insufficient analysis of how notions of mental health are shaped by power relations, and an over-reliance on therapy as a strategy for managing distress" (p. 14). She advocates for more critical analysis, which examines how psychiatric diagnosis and treatment occurs within "Eurocentric, masculine, and heterosexist norms and power relations" (p. 21).

Chapter Three presents the evolution and growing use of trauma-informed narratives within psychiatric settings. Tseris believes that there has sometimes been an uncritical acceptance that this has enhanced women's experience of mental health settings, and that there is still a need to consider symptoms of things such as Borderline Personality Disorder and Post Traumatic Stress Disorder 
within structural forms of oppression. She discusses the experiences of indigenous peoples as an example of how once intergenerational trauma may have been relegated to individual symptoms but is now understood more in relation to the effects of colonisation and ongoing racism.

Chapter Four considers some of the recent narratives in neuroscience and accepts that, while some feminists initially welcomed the apparent validation of the impacts of trauma (women maybe were not just making it up!) that there is a worrying trend to once again align trauma response to a medical view, and that women are encouraged to take responsibility for changing themselves, rather than looking to social and power structures that do not address violence against women in society. A consideration of negative presentations of impacts of trauma on mothering is also explored.

Chapter Five describes the results of a qualitative narrative research project exploring the views of women who have experienced gender-based violence and their experiences of navigating mental health services. This study revealed that most of her subjects $(\mathrm{n}=18)$ saw therapy as a tool for moving beyond their trauma experiences. Tseris argues that this is once again a reaction to discourses which value this approach and that there is often little else is available to women.
The final chapter considers alternative possibilities and the de-therapising approach to working with women who have experienced trauma. Tseris states that we must "explore both the hazards of pathologising women and enacting unwanted mental health interventions that medicalise women's experiences, while at the same time avoiding a cruel detachment from the immediate needs of women in distress" (p. 112). This brings us back to social work's mission of ensuring that the structural issues maintaining the problem of violence against women are considered in all areas and that interventions, which include social action, community development and provision of adequate resources for women to live safely, are all important.

While not always an "easy read," this is an important book for social workers and other social service and mental health practitioners to remind us of the ongoing importance of a critical feminist consideration of the work that we do, however well-intentioned we are. This is important so that we do not contribute to situating the problem within the person and forgetting about some of the important structural issues that enable violence against women and children to be perpetuated.

\section{References}

Dominelli, L. (2003). Anti-oppressive social work theory and practice. Macmillan Education UK.

Payne, M. (2021). Modern social work theory (5th ed.). Macmillan Education UK.

Reviewed by Barbara Staniforth, Senior Lecturer Social Work, The University of Auckland 